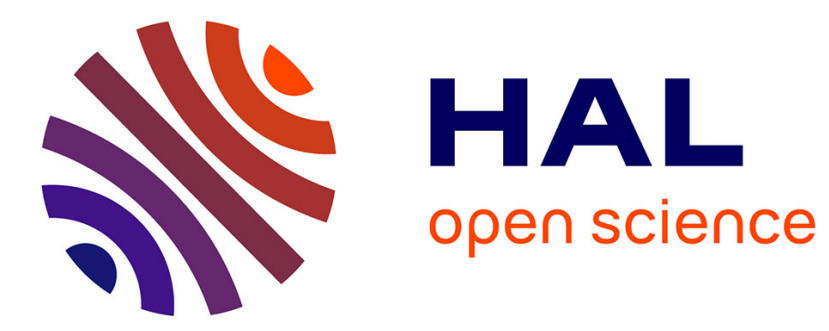

\title{
State estimation of stochastic singular linear systems : convergence and stability
}

Mohamed Darouach, André Bassong Onana, Michel Zasadzinski

\section{To cite this version:}

Mohamed Darouach, André Bassong Onana, Michel Zasadzinski. State estimation of stochastic singular linear systems: convergence and stability. International Journal of Systems Science, 1993, 24 (5), pp.1001-1008. hal-00143909

\section{HAL Id: hal-00143909 https://hal.science/hal-00143909}

Submitted on 27 Apr 2007

HAL is a multi-disciplinary open access archive for the deposit and dissemination of scientific research documents, whether they are published or not. The documents may come from teaching and research institutions in France or abroad, or from public or private research centers.
L'archive ouverte pluridisciplinaire HAL, est destinée au dépôt et à la diffusion de documents scientifiques de niveau recherche, publiés ou non, émanant des établissements d'enseignement et de recherche français ou étrangers, des laboratoires publics ou privés. 


\title{
State estimation of stochastic singular linear systems : convergence and stability
}

\author{
M. Darouach, A. Bassong Onana and M. Zasadzinski \\ CRAN - CNRS \\ IUT de Longwy, Université Henri Poincaré - Nancy I \\ 186, rue de Lorraine, 54400 Cosnes et Romain, FRANCE \\ Tel : +33 +3823962 22 - Fax : +33 + 382 396291 \\ E-mail : Mohamed.Darouach@iut-longwy.uhp-nancy.fr, Michel.Zasadzinskizasad@iut-longwy.uhp-nancy.fr
}

\begin{abstract}
In this paper, we present necessary and sufficient conditions of convergence of the Generalized Riccati equation and stability for the state estimator developped in [1].
\end{abstract}

Keywords : Stochastic singular systems, Optimal filtering, Least squares, Kalman filter, generalized Riccati equation, Convergence, Stability.

\section{Introduction}

In a recent paper, [1], we have developed a simple algorithm for the state estimation of stochastic singular linear systems based on the least squares method. In this paper, we shall consider the problem of convergence and stability of the obtained generalized Riccati equation and the associated state estimator. The approach is based on the orthogonal transformation and leads to a standard Riccati equation. The organization of this paper is as follows : section 2 contains a summary of main results, section 3 develops the method for the convergence and stability study, section 4 presents a numerical example and section 5 contains conclusion and remarks.

\section{Summary of the results}

Consider the stochastic singular linear system of the form

$$
\begin{aligned}
E x_{k+1} & =A x_{k}+w_{k} \\
z_{k} & =H x_{k}+v_{k}
\end{aligned}
$$

where $x_{k} \in \mathbb{R}^{n}$ is the state vector and $z_{k} \in \mathbb{R}^{m}$ is the output vector. $E \in \mathbb{R}^{p \times n}, A \in \mathbb{R}^{p \times n}$ and $H \in \mathbb{R}^{m \times n}$ are constant matrices (if $n=p, E$ may be singular). $w_{k}$ and $v_{k}$ are zero mean white sequences with

$$
\mathbb{E}\left\{\left[\begin{array}{l}
w_{k} \\
v_{k}
\end{array}\right]\left[\begin{array}{ll}
w_{j}^{T} & v_{j}^{T}
\end{array}\right]\right\}=\left[\begin{array}{cc}
W & 0 \\
0 & V
\end{array}\right] \delta_{k j}>0
$$

where $\delta_{k j}$ is the Kronecker delta.

In [1], we introduced the notion of estimability for system (1)-(2) and proved the following theorem.

Theorem 1. System (1)-(2) is estimable if and only if matrix $\left[\begin{array}{cc}E^{T} & H^{T}\end{array}\right]^{T}$ is of full column rank. 
In what follows, we assum that

$$
\operatorname{rank}\left[\begin{array}{c}
E \\
H
\end{array}\right]=n
$$

In this case, if the initial state $x_{0}$ is assumed to be gaussian with mean $\bar{x}_{0}$ and covariance $P_{0}>0$, uncorrelated with $w_{k}$ and $v_{k}$, then the recursive state estimator in the least squares sense is given by [1]

$$
\widehat{x}_{k / k}=P_{k / k} E^{T}\left(W+A P_{k-1 / k-1} A^{T}\right)^{-1} A \widehat{x}_{k-1 / k-1}+P_{k / k} H^{T} V^{-1} z_{k}
$$

where

$$
P_{k / k}=\left(E^{T}\left(W+A P_{k-1 / k-1} A^{T}\right)^{-1} E+H^{T} V^{-1} H\right)^{-1}
$$

is the estimation error covariance matrix, with $P_{0 / 0}=P_{0}$ and $\widehat{x}_{0 / 0}=\bar{x}_{0}$. Equation (4) represents a generalized Riccati difference equation (GRDE).

Now we can give the following results which play the key roles in the proof of the convergence of (4) and the stability of filter (3).

Theorem 2. Let

$$
\left[\begin{array}{l}
E \\
H
\end{array}\right]
$$

be $a(p+m) \times n$ matrix of rank $n$. There exists $a(p+m) \times(p+m)$ orthogonal matrix $T$ such that

$$
T\left[\begin{array}{c}
E \\
H
\end{array}\right]=\left[\begin{array}{c}
E_{1} \\
0
\end{array}\right]
$$

where $E_{1} \in \mathbb{R}^{n \times n}$ is a non-singular upper triangular matrix.

The proof of this theorem in given in [2].

Lemma 1. If

$$
\operatorname{rank}\left[\begin{array}{c}
E \\
H
\end{array}\right]=n
$$

then

$$
\operatorname{rank}\left[\begin{array}{c}
s E-A \\
H
\end{array}\right]=n \quad \forall s \in \mathbb{C},|s| \geqslant 1 \text { if } \operatorname{rank}\left[\begin{array}{c}
s I-E_{1}^{-1} A_{1} \\
A_{2}
\end{array}\right]=n \quad \forall s \in \mathbb{C},|s| \geqslant 1
$$

where

$$
\left[\begin{array}{l}
A_{1} \\
A_{2}
\end{array}\right]=T\left[\begin{array}{l}
A \\
0
\end{array}\right]
$$

Proof. If

$$
\operatorname{rank}\left[\begin{array}{c}
E \\
H
\end{array}\right]=n
$$

then, from Theorem 2, there exists an orthogonal matrix $T$ such that

$$
T\left[\begin{array}{c}
E \\
H
\end{array}\right]=\left[\begin{array}{c}
E_{1} \\
0
\end{array}\right]
$$

where $E_{1} \in \mathbb{R}^{n \times n}$ is a non-singular matrix. Then we have

$$
\begin{aligned}
\operatorname{rank}\left[\begin{array}{c}
s E-A \\
H
\end{array}\right] & =\operatorname{rank}\left[\begin{array}{c}
s E-A \\
s H
\end{array}\right]=\operatorname{rank}\left[\begin{array}{cc}
E_{1}^{-1} & 0 \\
0 & -I
\end{array}\right] T\left[\begin{array}{c}
s E-A \\
s H
\end{array}\right] \\
& =\operatorname{rank}\left[\begin{array}{cc}
E_{1}^{-1} & 0 \\
0 & -I
\end{array}\right]\left[\begin{array}{c}
s E_{1}-A_{1} \\
-A_{2}
\end{array}\right]=\operatorname{rank}\left[\begin{array}{c}
s I-E_{1}^{-1} A_{1} \\
A_{2}
\end{array}\right] \quad \forall s \in \mathbb{C},|s| \geqslant 1
\end{aligned}
$$




\section{Convergence and stability analysis}

In this section, we shall be interested in the question of the convergence of the filter (3)-(4), that is in the existence of the limiting solution $P$ of the GRDE (4). If this solution exists, then it satisfies the following generalized algebraic Riccati equation (GARE)

$$
P=\left(E^{T}\left(W+A P A^{T}\right)^{-1} E+H^{T} V^{-1} H\right)^{-1}
$$

and the asymptotic filter equation is

$$
\widehat{x}_{k / k}=P E^{T}\left(W+A P A^{T}\right)^{-1} A \widehat{x}_{k-1 / k-1}+P H^{T} V^{-1} z_{k}
$$

From the previous results and from [3], we can give the following theorem for the existence and uniquiness of the strong and the stabilizing solutions of the GARE. These solutions are defined as follows.

Definition 1. [Strong and stabilizing solutions] A strong solution of the GARE is a real symmetric non-negative definite solution for which the corresponding steady-state filter transition matrix has all its eigenvalues inside or on the unit circle. If all eigenvalues are inside the unit circle, the solution is called the stabilizing solution.

Theorem 3. If

$$
\operatorname{rank}\left[\begin{array}{c}
E \\
H
\end{array}\right]=n
$$

then the GARE has a unique strong solution if and only if

$$
\operatorname{rank}\left[\begin{array}{c}
s E-A \\
H
\end{array}\right]=n \quad \forall s \in \mathbb{C},|s| \geqslant 1
$$

Proof. Since

$$
\operatorname{rank}\left[\begin{array}{c}
E \\
H
\end{array}\right]=n
$$

by assumption, we have, from Theorem 2 ,

$$
T\left[\begin{array}{c}
E \\
H
\end{array}\right]=\left[\begin{array}{c}
E_{1} \\
0
\end{array}\right]
$$

where $T^{T} T=I$ and $E_{1} \in \mathbb{R}^{n \times n}$ with $\operatorname{det} E_{1} \neq 0$. The GARE can then be written

$$
\begin{aligned}
P^{-1} & =\left[\begin{array}{ll}
E^{T} & H^{T}
\end{array}\right]\left(\left[\begin{array}{cc}
W & 0 \\
0 & V
\end{array}\right]+\left[\begin{array}{c}
A \\
0
\end{array}\right] P\left[\begin{array}{ll}
A^{T} & 0
\end{array}\right]\right)^{-1}\left[\begin{array}{c}
E \\
H
\end{array}\right] \\
& =\left[\begin{array}{ll}
E^{T} & H^{T}
\end{array}\right]\left(\left[\begin{array}{ll}
Q_{1} & S_{1} \\
S_{1}^{T} & R_{1}
\end{array}\right]+\left[\begin{array}{l}
A_{1} \\
A_{2}
\end{array}\right] P\left[\begin{array}{ll}
A_{1}^{T} & A_{2}^{T}
\end{array}\right]\right)^{-1}\left[\begin{array}{c}
E_{1} \\
0
\end{array}\right]
\end{aligned}
$$

where

$$
\left[\begin{array}{l}
A_{1} \\
A_{2}
\end{array}\right]=T\left[\begin{array}{c}
A \\
0
\end{array}\right] \text { and }\left[\begin{array}{ll}
Q_{1} & S_{1} \\
S_{1}^{T} & R_{1}
\end{array}\right]=T\left[\begin{array}{cc}
W & 0 \\
0 & V
\end{array}\right] T^{T}
$$

The inverse of partitioned matrices applied to (5) gives

$$
P^{-1}=E_{1}^{T}\left(Q_{1}+A_{1} P A_{1}^{T}-\left(S_{1}+A_{1} P A_{2}^{T}\right)\left(R_{1}+A_{2} P A_{2}^{T}\right)^{-1}\left(S_{1}+A_{1} P A_{2}^{T}\right)^{T}\right)^{-1} E_{1}
$$

or equivalently, since $E_{1}$ is non-singular

$$
P=Q+F P F^{T}-\left(S+F P C^{T}\right)\left(R+C P C^{T}\right)^{-1}\left(S+F P C^{T}\right)^{T}
$$


with $Q=E_{1}^{-1} Q_{1} E_{1}^{-T}, F=E_{1}^{-1} A_{1}, S=E_{1}^{-1} S_{1}, C=A_{2}$ and $R=R_{1}$.

Equation (6) is the algebraic Riccati equation of the standard Kalman filter where the measurement erros and the model errors are correlated $[4,5]$. This case can be handled like the uncorrelated case by defining

$$
\begin{aligned}
F_{s} & =F-S R^{-1} C \\
Q_{s} & =Q-S R^{-1} S^{T}
\end{aligned}
$$

so that (6) becomes

$$
P=Q_{s}+F_{s} P F_{s}^{T}-F_{s} P C^{T}\left(R+C P C^{T}\right)^{-1} C P F_{s}^{T}
$$

From Theorem 3.2 in [3], the strong solution of $(7)$ exists and is unique if and only if $\left(C, F_{s}\right)$ is detectable. This is equivalent to

$$
\operatorname{rank}\left[\begin{array}{c}
s I-F_{s} \\
C
\end{array}\right]=\operatorname{rank}\left[\begin{array}{c}
s I-E_{1}^{-1} A_{1} \\
A_{2}
\end{array}\right]=n \quad \forall s \in \mathbb{C},|s| \geqslant 1
$$

and from Lemma 1, we have

$$
\operatorname{rank}\left[\begin{array}{c}
s E-A \\
H
\end{array}\right]=n \quad \forall s \in \mathbb{C},|s| \geqslant 1
$$

The same orthogonal transformation applied to the filter (3) and the GRDE (4) gives

$$
\begin{aligned}
\widehat{x}_{k / k}= & P_{k / k}\left[\begin{array}{ll}
E^{T} & H^{T}
\end{array}\right]\left(\left[\begin{array}{cc}
W & 0 \\
0 & V
\end{array}\right]+\left[\begin{array}{c}
A \\
0
\end{array}\right] P_{k-1 / k-1}\left[\begin{array}{ll}
A^{T} & 0
\end{array}\right]\right)^{-1}\left(\left[\begin{array}{c}
A \\
0
\end{array}\right] \widehat{x}_{k-1 / k-1}+\left[\begin{array}{c}
0 \\
I
\end{array}\right] z_{k}\right) \\
= & \left(F-\left(S+F P_{k-1 / k-1} C^{T}\right)\left(R+C P_{k-1 / k-1} C^{T}\right)^{-1} C\right) \widehat{x}_{k-1 / k-1} \\
& +\left(E_{1}^{-1} B_{1}-\left(S+F P_{k-1 / k-1} C^{T}\right)\left(R+C P_{k-1 / k-1} C^{T}\right)^{-1} B_{2}\right) z_{k}
\end{aligned}
$$

and

$$
P_{k / k}=Q_{s}+F_{s} P_{k-1 / k-1} F_{s}^{T}-F_{s} P_{k-1 / k-1} C^{T}\left(R+C P_{k-1 / k-1} C^{T}\right)^{-1} C P_{k-1 / k-1} F_{s}^{T}
$$

with

$$
\left[\begin{array}{l}
B_{1} \\
B_{2}
\end{array}\right]=T\left[\begin{array}{l}
0 \\
I
\end{array}\right]
$$

The convergence conditions of the GRDE (4) and the stability of filter (3) are given by the following theorem.

Theorem 4. Subject to $P_{0}>0$, then the detectability of $(C, F)$, or equivalently

$$
\operatorname{rank}\left[\begin{array}{c}
s E-A \\
H
\end{array}\right]=n \quad \forall s \in \mathbb{C},|s| \geqslant 1
$$

and the non-existence of unreachable mode of $\left(F_{s}, D\right)$ (where $D$ is any square-root of $Q_{s}$ ) on the unit circle are the necessary and sufficient conditions for

$$
\lim _{k \rightarrow \infty} P_{k / k}=P \text { (exponentially fast) }
$$

where $P$ is the unique solution of the GARE.

Proof. Since (3) and (4) are equivalent to (8) and (9), the proof is given by [3]. 


\section{Numerical example}

As an numerical example, we consider the singular discrete-time system used in [1], described by

$$
\begin{aligned}
E x_{k+1} & =A x_{k}+w_{k} \\
z_{k} & =H x_{k}+v_{k}
\end{aligned}
$$

where

$$
\begin{aligned}
& E=\left[\begin{array}{cccc}
1 & 1 & 1 & 0 \\
2 & 0 & -1 & 0 \\
0 & 1 & 0 & 1
\end{array}\right], A=\left[\begin{array}{cccc}
1 & 1 & 0 & 0.59 \\
0 & -1 & 0 & 0.50 \\
1 & 0 & 1 & 0.09
\end{array}\right], H=\left[\begin{array}{cccc}
1 & 0 & 0 & 1 \\
0 & 1 & -0.5 & 0 \\
0 & 0 & 0 & 1
\end{array}\right] \\
& W=\left[\begin{array}{ccc}
0.6 & 0 & 0 \\
0 & 0.8 & 0 \\
0 & 0 & 0.7
\end{array}\right], V=\left[\begin{array}{ccc}
0.3 & 0 & 0 \\
0 & 0.3 & 0 \\
0 & 0 & 0.6
\end{array}\right]
\end{aligned}
$$

It is easy to verify that

$$
\operatorname{rank}\left[\begin{array}{c}
E \\
H
\end{array}\right]=4 \text { and } \operatorname{rank}\left[\begin{array}{c}
s E-A \\
H
\end{array}\right]=4 \quad \forall s \in \mathbb{C},|s| \geqslant 1
$$

From theorem 3, the GARE has a unique strong solution $P$.

We used the QR factorization to determine the orthogonal transformation $T$

$$
T=\left[\begin{array}{cccccc}
-0.408 & -0.816 & 0 & -0.408 & 0 & 0 \\
0.495 & -0.198 & 0.594 & -0.099 & 0.594 & 0 \\
0.699 & -0.424 & -0.169 & 0.148 & -0.530 & 0 \\
0.247 & 0.151 & -0.437 & -0.550 & 0.190 & -0.621 \\
0.042 & -0.245 & -0.616 & 0.449 & 0.574 & 0.167 \\
0.191 & 0.177 & -0.220 & -0.545 & 0.029 & 0.765
\end{array}\right]
$$

By using the same notations as in the above study, we have

$$
\begin{aligned}
& A_{1}=\left[\begin{array}{cccc}
-0.408 & 0.408 & 0 & -0.649 \\
1.089 & 0.693 & 0.594 & 0.246 \\
0.530 & 1.123 & -0.169 & 0.185 \\
-0.190 & 0.095 & -0.437 & 0.182
\end{array}\right], A_{2}=\left[\begin{array}{cccc}
-0.574 & 0.287 & -0.616 & -0.153 \\
-0.029 & 0.014 & -0.220 & 0.181
\end{array}\right], \\
& F=\left[\begin{array}{cccc}
0.123 & 0.062 & -0.115 & 0.281 \\
0.522 & 0.239 & 0.301 & 0.149 \\
0.383 & 0.808 & -0.118 & 0.132 \\
0.118 & -0.059 & 0.271 & -0.113
\end{array}\right], Q=\left[\begin{array}{cccc}
0.129 & -0.020 & 0.027 & -0.056 \\
-0.020 & 0.180 & -0.016 & -0.024 \\
0.027 & -0.016 & 0.284 & -0.019 \\
-0.056 & -0.024 & -0.019 & 0.202
\end{array}\right] \text {, } \\
& R=\left[\begin{array}{ll}
0.491 & 0.073 \\
0.073 & 0.522
\end{array}\right], S=\left[\begin{array}{cc}
-0.008 & 0.040 \\
-0.075 & -0.042 \\
0.073 & 0.013 \\
-0.038 & 0.048
\end{array}\right], Q_{s}=\left[\begin{array}{cccc}
0.126 & -0.019 & 0.028 & 0.061 \\
-0.019 & 0.166 & 0.004 & -0.027 \\
0.028 & -0.004 & 0.273 & -0.014 \\
-0.061 & -0.027 & -0.014 & 0.193
\end{array}\right] \text {, }
\end{aligned}
$$




$$
F_{s}=\left[\begin{array}{cccc}
0.110 & -0.055 & 0.114 & 0.262 \\
0.438 & 0.281 & 0.199 & 0.138 \\
0.469 & 0.765 & -0.025 & 0.154 \\
0.068 & -0.034 & 0.237 & -0.146
\end{array}\right], D=\left[\begin{array}{cccc}
0.343 & -0.029 & 0.031 & -0.080 \\
-0.029 & 0.405 & -0.004 & -0.035 \\
0.031 & -0.004 & 0.521 & -0.012 \\
-0.080 & -0.035 & -0.012 & 0.431
\end{array}\right]
$$

The non-existence of unreacheable mode of $\left(F_{s}, D\right)$ is verified since the rank of the contrallability matrix $\left[\begin{array}{llll}D & \left(F_{s} D\right) & \left(F_{s}^{2} D\right) & \left(F_{s}^{3} D\right)\end{array}\right]$ is 4 .

With $P_{0}=I>0$, we conclude, from Therem 4 , that $P$ is the unique stabilizing solution of the GARE. For this initialization, the trace of $P_{k / k}$ is plotted in figure 1 . The obtained value for $P$ is

$$
P=\left[\begin{array}{cccc}
0.141 & -0.028 & 0.017 & -0.077 \\
-0.028 & 0.216 & 0.059 & -0.008 \\
0.017 & 0.059 & 0.400 & -0.005 \\
-0.077 & -0.008 & -0.005 & 0.216
\end{array}\right]
$$

The spectral radius of the filter state transition matrix is

$$
\rho\left(P E^{T}\left(W+A P A^{T}\right)^{-1} A\right)=0.4446
$$

which shows that the filter is stable.

\section{Conclusion}

In this paper, a new approach for studying the convergence and stability of the generalized filter developed for stochastic singular linear systems is proposed. The method uses an orthogonal transformation of the pair $(E, H)$ and leads to the standard algebraic Riccati equation. The necessary and sufficient conditions of convergence and stability are derived.

\section{References}

[1] M. Darouach, M. Zasadzinski, and D. Mehdi, "State estimation of stochastic singular linear systems," Int. J. Syst. Sci., vol. 24, pp. 345-354, 1993.

[2] C. Lawson and R. Hanson, Solving Linear Least Squares Problems. Englewood Cliffs, New Jersey: Prentice Hall, 1974.

[3] C. de Souza, M. Gevers, and G. Goodwin, "Riccati equations in optimal filtering of nonstabilizable systems having singular state transition matrices," IEEE Trans. Aut. Contr., vol. 31, pp. 831-838, 1986.

[4] P. Caines, Linear Stochastic Systems. New York: Wiley, 1988.

[5] S. Chan, G. Goodwin, and K. Sin, "Convergence properties of the riccati difference equation in optimal filtering of nonstabilizable systems," IEEE Trans. Aut. Contr., vol. 29, pp. 110-118, 1984. 


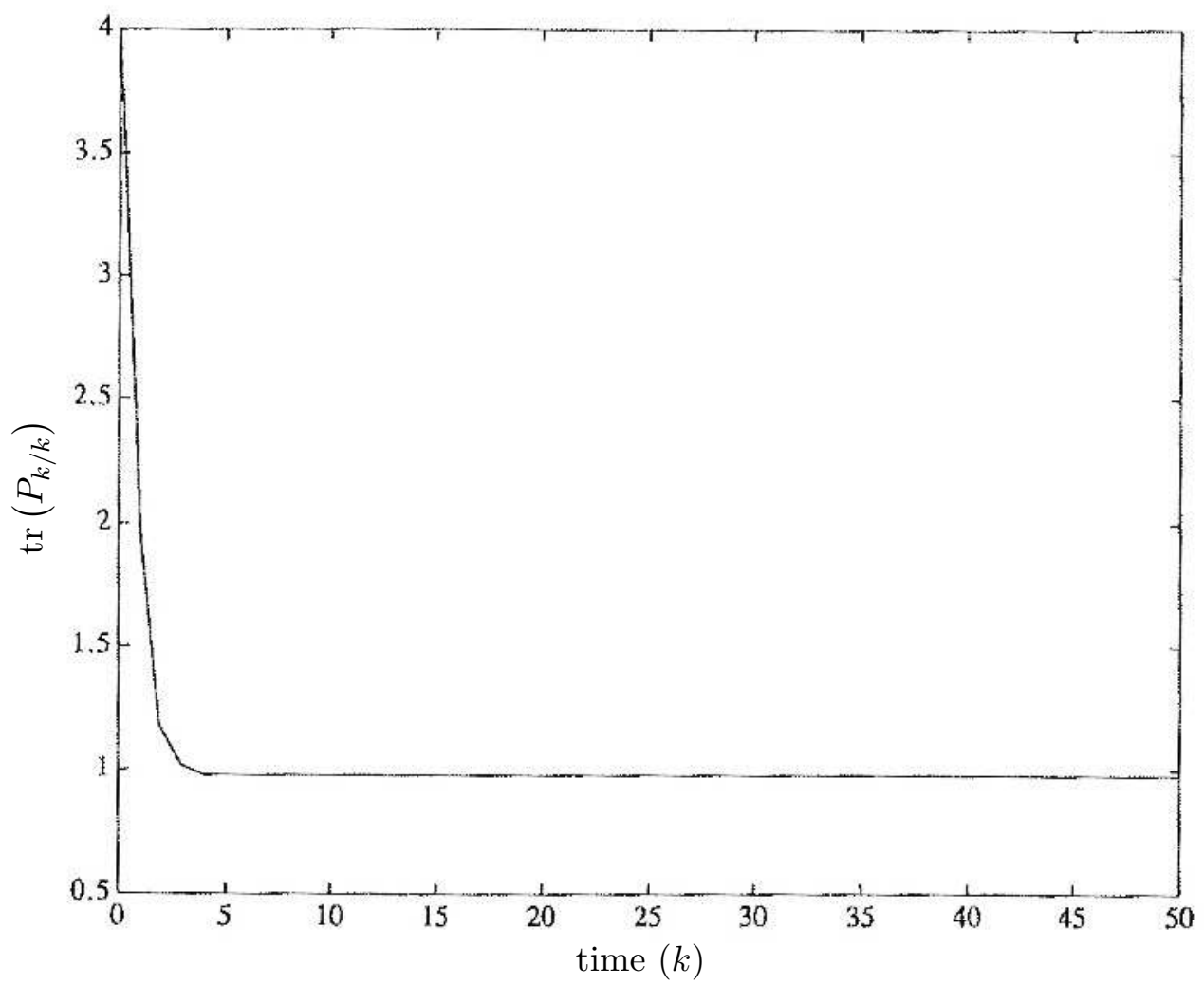

Figure 1: Convergence of the filter. 